Check for updates

Cite this: RSC Adv., 2018, 8, 10907

Received 20th January 2018

Accepted 26th February 2018

DOI: $10.1039 / c 8 r a 00584 b$

rsc.li/rsc-advances

\title{
Insight into the efficient catalytic conversion of biomass to EG and 1,2-PG over W-Ni bimetallic catalyst
}

\author{
Meng-Qing Li, Yu-Long Ma, (D) * Xiao-Xia Ma, Yong-Gang Sun and Zhi Song
}

In this work, a mesoporous silica microsphere (MSM) was selected as a support to prepare a bimetallic supported catalyst ( $15 \% \mathrm{~W}-5 \% \mathrm{Ni} / \mathrm{MSM})$ by a co-impregnation method that was simple and easy to conduct. We wished to improve the capability of catalytic conversion of biomass into ethylene glycol (EG) and 1,2-propylene glycol (1,2-PG). 15\% W-5\% Ni/MSM was examined on microcrystalline cellulose (cellulose) and corn stalks in a one-pot catalytic process, and total yields of EG and 1,2-PG reached up to $82.40 \mathrm{wt} \%$ and $62.60 \mathrm{wt} \%$, respectively. This remarkable catalytic performance of W-Ni/MSM catalyst could be attributed to the synergistic effect between the active sites of $\mathrm{Ni}$ and $\mathrm{W}$ and the unique structure of MSM, which was suitable for mass transfer and metal loading. Based on physicochemical characterizations, the metal component was well-distributed on the surface of the MSM, and the metallic $\mathrm{Ni}, \mathrm{W}$ and $\mathrm{WO}_{3}$ of the fresh catalyst were converted mainly into $\mathrm{NiWO}_{4}$ during the catalytic conversion of cellulose. To shed light on the reaction mechanism of the catalyzed hydrogenation of biomass, a possible process involving the formation of $\mathrm{H}_{x} \mathrm{WO}_{3}$ homogeneous catalysts, cellulose hydrolysis, C-C cleavage and hydrogenation conversion to 1,2-PG and EG was illustrated. Furthermore, the reusability of $\mathrm{W}-\mathrm{Ni} / \mathrm{MSM}$ catalyst was tested and we explored the cause of decreased diols yields. In summary, this work provides important guidance to rationally design effective catalysts for biomass conversion.

\section{Introduction}

Lignocellulose has been considered as a "clean energy" resource because it could solve the pollution problem and the global warming caused by the consumption of fossil fuels. ${ }^{1,2}$ Recently, the catalytic conversion of biomass into highly valued chemicals has appealed to researchers. These include ethylene glycol (EG) and 1,2-propylene glycol (1,2-PG), which are very important "platform molecules" with a very large market demand. ${ }^{3-5}$ Among the strategies of biomass transformation into polyols, one-pot chemical conversion has proved to be a better choice for high efficiency and environmental protection..$^{6-8}$ Under hydrogen pressure in aqueous solution, cellulose can be converted into smaller molecules directly, which overcomes the effect of the crystalline structure with the linkage of $\beta-1,4-$ glycosidic bonds and hydrogen bonds. ${ }^{9,10}$ Fukuoka and coworkers reported that the one-pot conversion of cellulose obtained a $31.0 \mathrm{wt} \%$ yield of hexitols on a $\mathrm{Pt} / \mathrm{Al}_{2} \mathrm{O}_{3}$ catalyst. ${ }^{11}$ Luo et al. raised the yield of hexitols to $39.3 \mathrm{wt} \%$ on a $\mathrm{Ru} / \mathrm{AC}$ catalyst in the same way. ${ }^{12}$ These results revealed that the

State Key Laboratory of High-efficiency Utilization of Coal and Green Chemical Engineering, College of Chemistry and Chemical Engineering, Ningxia University, Yinchuan, 750021, China. E-mail: yulongma796@sohu.com; Fax: +86951 2062859; Tel: +869512062859 hydrolytic hydrogenation of cellulose into sugar alcohol products over noble metal catalysts exhibited considerable catalytic ability. In addition, Zhang et al. found that the catalytic conversion of cellulose was excellent ( $65.0 \mathrm{wt} \%$ yield of EG) on a supported tungsten carbide catalyst in a one-pot process; this is the "frontline" of the biomass-based energy field because of the distinctive selectivity of EG..$^{13}$ In this instance, it was found that the activity of the catalyst was improved remarkably by the addition of Ni species to tungsten catalysts, and this catalytic performance was better than that of noble metal catalysts. ${ }^{14-16}$ Moreover, various supports were exploited to enhance the capability of nickel-tungsten catalysts, including $\mathrm{Al}_{2} \mathrm{O}_{3}, \mathrm{Al}_{2} \mathrm{O}_{3}{ }^{-}$ $\mathrm{SiO}_{2},{ }^{17} \mathrm{MOR},{ }^{18}$ and SBA-15. ${ }^{19}$ These results suggested that the synergistic action of the active metal and support had an important impact on the catalytic reaction of cellulose, and could become a promising research direction. However, the study on the reaction pathway of cellulose conversion into polyol was inadequate. As noted above, design of an efficient catalyst and research of the reaction mechanism on the hydrolytic hydrogenation of cellulose into polyols are crucial. When considering interactions between the active site and support, a mesoporous silica microsphere (MSM) is an ideal candidate to design supported $\mathrm{W}-\mathrm{Ni}$ catalysts because of its uniform mesoporous structure, large specific surface area, and pore volume. In particular, the surface structure of a MSM can 
play a vital part in good chemical durability and high active area for metal deposition, which promotes the synergistic action of the active metal and MSM. ${ }^{20-23}$ The active sites of $\mathrm{Ni}$ and $\mathrm{W}$ could improve stability and capability through loading on the MSM support, which could accelerate the reaction rate of the catalytic conversion of biomass into polyols.

We wished to improve the catalytic performance of $\mathrm{Ni}-\mathrm{W}$ catalyst and study the reaction mechanism for the direct conversion of biomass into EG and 1,2-PG. Then, microcrystalline cellulose and samples of pretreated corn stalk were subjected to catalyzed hydrogenation under optimal conditions, respectively. Moreover, the recycling test for catalytic activity was done based on the characterizations of a high-pressure reactor, high-performance liquid chromatography (HPLC), Xray diffraction (XRD) spectroscopy, X-ray photoelectron spectroscopy (XPS), transmission electron microscopy (TEM), scanning electron microscopy (SEM) and the $\mathrm{N}_{2}$ adsorptiondesorption.

\section{Experimental}

\subsection{Materials}

Microcrystalline cellulose, ammonia metatungstate (AMT) and nickel nitrate hexahydrate $\left[\mathrm{Ni}\left(\mathrm{NO}_{3}\right)_{2} \cdot 6 \mathrm{H}_{2} \mathrm{O}\right]$ were purchased from Aladdin Chemistry Co. Ltd (China). MSMs were obtained from NewMater Nanotechnology Co. Ltd (China). Corn stalks were from the Helan Ranch in Yinchuan (Ningxia, China). All chemical reagents were of analytic grade. All experiments were carried out in triplicate and mean data are shown.

\subsection{Catalyst synthesis}

The Ni-W catalyst supported on MSMs was prepared by an impregnation method using an aqueous solution of AMT and $\mathrm{Ni}\left(\mathrm{NO}_{3}\right)_{2} \cdot 6 \mathrm{H}_{2} \mathrm{O}$ with stirring for $10 \mathrm{~h}$ at room temperature (RT), and the $\mathrm{Ni}$ and $\mathrm{W}$ loadings were $5.0 \mathrm{wt} \%$ and $15.0 \mathrm{wt} \%$, respectively. After impregnation, the samples were dried at $120{ }^{\circ} \mathrm{C}$ for $12 \mathrm{~h}$ followed by calcination in an air atmosphere at $500{ }^{\circ} \mathrm{C}$ for $3 \mathrm{~h}$ (ramp rate of $2{ }^{\circ} \mathrm{C} \mathrm{min}^{-1}$ ), and then reduced in a hydrogen atmosphere at $700{ }^{\circ} \mathrm{C}$ for $1 \mathrm{~h}$ (ramp rate of

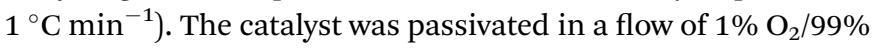
$\mathrm{N}_{2}$ for $10 \mathrm{~h}$ at RT. Finally, the bimetallic catalyst with catalytic hydrogenation function was obtained and denoted as " $15 \% \mathrm{~W}$ $5 \% \mathrm{Ni} / \mathrm{MSM}$ ". A control sample was also obtained.

\subsection{Pretreatment on corn stalks}

Raw corn stalks were chopped into pieces of size $\approx 1 \mathrm{~cm}$, milled using a fodder grinder, passed through a sieve ( 80 mesh), and stored for further treatment. The main composition of the untreated corn stalk was 42.02 wt $\%$ cellulose, 15.88 wt $\%$ hemicellulose, $12.17 \mathrm{wt} \%$ acid-insoluble lignin (AIL), $15.87 \mathrm{wt} \%$ acid-soluble lignin (ASL), $3.50 \mathrm{wt} \%$ ash, and $9.96 \mathrm{wt} \%$ other material. Then, the samples of raw corn stalks were pretreated with $\mathrm{H}_{2} \mathrm{SO}_{4}$ and $\mathrm{NaOH}$ solution on the reactor. Alkali pretreatment was operated with $2.0 \mathrm{wt} \% \mathrm{NaOH}$ for $4 \mathrm{~h}$ at $80{ }^{\circ} \mathrm{C}$. Acid pretreatment was operated with $5.0 \mathrm{wt} \% \mathrm{H}_{2} \mathrm{SO}_{4}$ for $6 \mathrm{~h}$ at $80{ }^{\circ} \mathrm{C}$. After pretreatment, the mixture was filtered. The solid was washed with deionized water until a neutral $\mathrm{pH}$ was reached, and then it was dried in air at $60{ }^{\circ} \mathrm{C}$ overnight. This method has been described in previous studies from our research team. ${ }^{\mathbf{2 4 - 2 6}}$

\subsection{Catalyst reaction and evaluation}

All catalytic experiments were conducted in a stainless-steel autoclave with $100 \mathrm{~mL}$ capacity. Initially, $0.3 \mathrm{~g}$ of reactant was mixed with catalyst in $60 \mathrm{~mL}$ of deionized water and then hydrogen was introduced. The reaction mixture was well-mixed with a magnetic stirrer (900 rpm). After the reaction, the reactor was quenched to RT in an ice water bath. After filtration of solid residues, the aqueous solution was filtered further with a 0.22 $\mu \mathrm{m}$ syringe filter and analyzed by HPLC with a refraction index detector (Shimadzu, Japan) and an InertSustain ${ }^{\mathrm{TM}}$ C18 column. Leaching of $\mathrm{W}$ and the Ni content of the filtrate obtained from the first run reaction were determined by inductively coupled plasma atomic emission spectroscopy (ICP-AES). The conversion of cellulose was determined by measuring the weight difference of the solid before and after the reaction, assuming that the catalyst weight was unchanged before and after the reaction. The yield and the selectivity of EG and 1,2-PG products were calculated based on the following equation, respectively:

$$
\begin{gathered}
\text { EG yield }\left(\mathrm{wt}^{\circ} \%\right)=\left[(E \times V) /\left(M_{0} \times X_{\mathrm{i}}\right)\right] \times 100 \\
\text { 1,2-PG yield }(\mathrm{wt} \%)=\left[(P \times V) /\left(M_{0} \times X_{\mathrm{i}}\right)\right] \times 100 \\
\text { Selectivity }(\mathrm{EG} / \%)=\left(n_{\mathrm{i}} \times 2 / n_{0}\right) \times 100 \\
\text { Selectivity }(1,2-\mathrm{PG} / \%)=\left(n_{\mathrm{i}} \times 3 / n_{0}\right) \times 100
\end{gathered}
$$

where $E\left(\mathrm{mg} \mathrm{mL}^{-1}\right)$ and $P\left(\mathrm{mg} \mathrm{mL}^{-1}\right)$ are EG and 1,2-PG produced during the catalysis, respectively. $V(\mathrm{~mL})$ is the total volume of reaction liquid. $M_{0}(\mathrm{mg})$ is the mass of raw material. $X_{\mathrm{i}}(\mathrm{wt} \%)$ is the cellulose weight fraction of the raw material. $n_{\mathrm{i}}$ is the carbon moles of EG and 1,2-PG products, respectively. $n_{0}$ is the total carbon moles of converted cellulose.

To evaluate the stability and reusability of the catalyst, the obtained solid was washed thrice using deionized water and dried overnight at $100{ }^{\circ} \mathrm{C}$ in a vacuum, followed by calcination at $450{ }^{\circ} \mathrm{C}$ in an air atmosphere for $3 \mathrm{~h}$ to remove the deposited carbon and to form the precursor. Then, the precursor was reduced in a hydrogen atmosphere.

\subsection{Characterization}

The XRD pattern of the samples were recorded on a Dmax2200PC (Rigaku, Japan) diffractometer equipped with a $\mathrm{Cu} K \propto 1$ radiation source $(\lambda=0.1540 \mathrm{~nm})$, operating at $40 \mathrm{kV}$ and $40 \mathrm{~mA}$. The chemical structure and morphology of the sample were characterized using SEM, TEM and energydispersive X-ray (EDX) spectroscopy with a JEM 2010 EX microscope (JEOL, Japan) at an accelerating voltage of $200 \mathrm{kV}$. The surface chemical compositions of samples were analyzed by XPS by an Escalab 250Xi spectrometer (Thermo Scientific, USA) with $\mathrm{Al} \mathrm{K} \alpha$ radiation. The binding energy was referenced to the C 1s peak at $284.8 \mathrm{eV} . \mathrm{N}_{2}$ adsorption-desorption experiments were undertaken at $77 \mathrm{~K}$ with an ASAP2010 surface area analyzer 
(Micrometrics, USA). Specific surface areas were obtained using the Brunauer-Emmett-Teller (BET) method. Pore volumes were calculated from $\mathrm{N}_{2}$ adsorption-desorption isotherms. Pore diameters and size distributions were determined using the Barret-Joyner-Halenda (BJH) method.

\section{Results and discussion}

\subsection{Characterization of catalysts}

The XRD spectroscopy patterns of the MSM before and after loading of $\mathrm{Ni}$ and $\mathrm{W}$ are shown in Fig. 1. The MSM had a broad peak at $\approx 23^{\circ}$, which is assigned to silica species. The peak remained when tungsten and nickel were added to the support, suggesting that the MSM structure was maintained during catalyst preparation. After loading of $\mathrm{Ni}$ and $\mathrm{W}$, the sample showed strong diffraction peaks relevant to the crystal structure of Wolfram (PDF\#04-0806) and the characteristic reflections appeared at $2 \theta$ at $40.3^{\circ}, 58.3^{\circ}$ and $73.3^{\circ}$, corresponding to the diffractions from (110), (200), and (211) planes, respectively. Three weak peaks at $2 \theta$ at $44.36^{\circ}, 51.59^{\circ}$ and $76.0^{\circ}$ are subsistent and visible even at low Ni loading. These three peaks correspond to nickel (PDF\#04-0850). XRD spectroscopy revealed metallic nickel and tungsten to already being formed on the supported catalyst. The XRD spectroscopy results of the synthesized $\mathrm{W}-\mathrm{Ni}$ bimetallic catalyst do not mean that both component metals were present in a zero-valence state. Fig. 2 displays the morphologies and microstructures of the MSM and $15 \% \mathrm{~W}-5 \% \mathrm{Ni} / \mathrm{MSM}$ catalyst. As shown in Fig. 2(a) and (d), the MSM structure had a smooth surface and regular spherical shape of size $\approx 300 \mathrm{~nm}$. As compared with the TEM images of the MSM [Fig. 2(b) and (c)] and W-Ni/MSM [Fig. 2(e) and (f)], it is obvious that the species of $\mathrm{Ni}$ and $\mathrm{W}$ were well distributed on the surface of the MSM. As shown in Fig. 2(g)-(i), a detailed analysis was employed using elemental mapping with EDX spectroscopy, which revealed that $\mathrm{Si}, \mathrm{Ni}$ and $\mathrm{W}$ were highly dispersed on the support. These results implied that the $15 \%$ W-5\% Ni/MSM catalyst was synthesized, which was in good accordance with the XRD spectroscopy results.

\subsection{Catalytic conversion of microcrystalline cellulose on $15 \%$ W-5\% Ni/MSM}

The catalytic conversion of microcrystalline cellulose (cellulose) was examined in a one-pot process. A non-catalytic experiment with cellulose was conducted first to determine the activity in

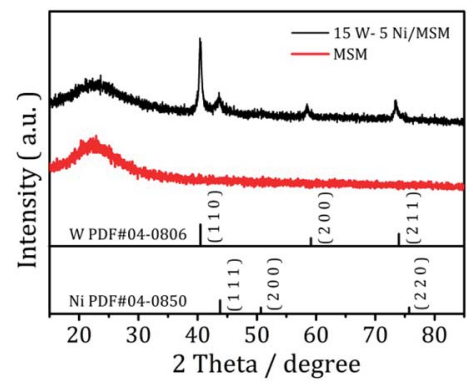

Fig. 1 XRD patterns of MSMs before and after loading of $\mathrm{Ni}$ and $\mathrm{W}$.

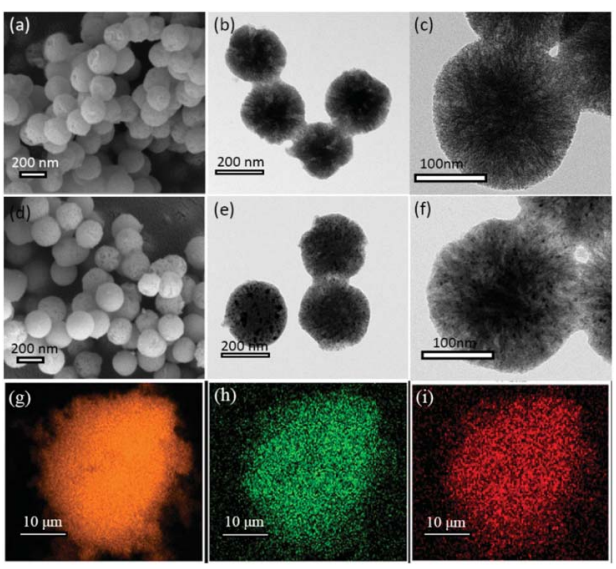

Fig. 2 Scanning electron microscope, transmission electron microscopy, and energy-dispersive X-ray spectroscopy of MSM and W-Ni/ MSM catalyst. (a) SEM and (b, c) TEM of MSM, (d) SEM, and (e, f) TEM of $\mathrm{W}-\mathrm{Ni} / \mathrm{MSM}$ catalyst. EDX elemental mapping images of $\mathrm{W}-\mathrm{Ni} / \mathrm{MSM}$ catalyst, (g) Si, (h) Ni and (i) W.

the absence of a catalyst. Cellulose was barely converted into EG (2.63 wt\%) and 1,2-PG (2.32 wt\%), with conversion of cellulose $>75 \%$ (Table 1). These data suggested that cellulose was converted mainly into a large fraction of unidentified unsaturated products and dissolved in a solvent lacking the catalytic conversion. ${ }^{\mathbf{1 3}}$ Under identical conditions, the experiments were also carried out over $5 \% \mathrm{Ni} / \mathrm{MSM}, 15 \% \mathrm{~W} / \mathrm{MSM}$ and $15 \% \mathrm{~W}-5 \%$ $\mathrm{Ni} / \mathrm{MSM}$ catalysts to evaluate the effect of the metal component. Notably, full conversion of cellulose and a diols yield, including EG and 1,2-PG, up to $41.85 \mathrm{wt} \%$ were obtained on $15 \% \mathrm{~W}-5 \%$ $\mathrm{Ni} / \mathrm{MSM}$ catalyst. Comparison with the diols yield on $5 \% \mathrm{Ni}$ / MSM (11.00 wt\%) and 15\% W/MSM (27.97 wt\%) suggested that the bimetallic catalyst had excellent catalytic activity with respect to monometallic catalysts. Furthermore, the effect of the amount of catalyst on cellulose conversion to EG and 1,2-PG was investigated (Fig. 3(a)). The diols yield increased rapidly from $41.85 \mathrm{wt} \%$ to $82.40 \mathrm{wt} \%$ with increasing weight of catalyst from 0.10 to $0.45 \mathrm{~g}$. Remarkably, the EG yield increased from $27.94 \mathrm{wt} \%$ to $72.90 \mathrm{wt} \%$. In particular, the selectivity of EG was up to $66.95 \%$ but the best selectivity of 1,2-PG was relatively lower (11.84 wt\%), which could indicate that selective conversion of cellulose into EG was sensitive over 15\% W-5\% Ni/MSM catalyst. Also, a greater amount of catalyst means more active

Table 1 Catalytic conversion of cellulose into EG and 1,2-PG over different catalysts ${ }^{a}$

\begin{tabular}{|c|c|c|c|c|c|}
\hline \multirow[b]{2}{*}{ Catalyst } & \multicolumn{2}{|l|}{ EG } & \multicolumn{2}{|l|}{ 1,2-PG } & \multirow{2}{*}{$\frac{\text { Conv. }}{\%}$} \\
\hline & $\mathrm{mg} \mathrm{L}^{-1}$ & $\%$ & $\mathrm{mg} \mathrm{L}^{-1}$ & $\%$ & \\
\hline Black & 131.51 & 2.63 & 116.02 & 2.32 & 76.38 \\
\hline Ni/MSM & 137.92 & 2.76 & 412.23 & 8.24 & 86.05 \\
\hline W/MSM & 1003.10 & 20.06 & 395.34 & 7.91 & 96.93 \\
\hline W-Ni/MSM & 1397.11 & 27.94 & 695.51 & 13.91 & 100.00 \\
\hline
\end{tabular}

${ }^{a}$ Conv.: conversion of cellulose, reaction conditions: microcrystalline cellulose $0.3 \mathrm{~g}$, catalyst $0.1 \mathrm{~g}$, deionized water $60 \mathrm{~mL}, 245{ }^{\circ} \mathrm{C}, 2 \mathrm{~h}$, $6.0 \mathrm{MPa} \mathrm{H}_{2}$. 

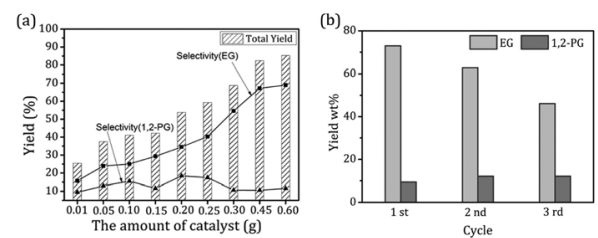

Fig. 3 (a) Catalytic result with different amounts and (b) the reusability of $\mathrm{W}-\mathrm{Ni} / \mathrm{MSM}$ catalyst for cellulose conversion.

sites on the catalyst, which enhanced the contact between the catalyst and cellulose, which is beneficial to efficient catalytic conversion. ${ }^{27}$ The reason for the good catalytic performance of $15 \% \mathrm{~W}-5 \% \mathrm{Ni} / \mathrm{MSM}$ could be attributed to the mesoporous pores and spherical structure of the MSM, and the synergistic effect of active metal (W and Ni component) and support, which can increase the rate of mass-transfer on the catalyst surface and decrease carbon deposition. ${ }^{22,23}$ However, only a small increase in cellulose conversion was obtained when the mass of the catalyst was increased from $0.45 \mathrm{~g}$ to $0.60 \mathrm{~g}$, and the combined yield of EG and 1,2-PG increased slightly (2.84 wt\%). The reason for this result may be that a heavy load of catalysts provides more active sites on the catalyst than that required by the feedstock. Thus, the excess catalyst caused side reactions such as polymerization and rehydration. ${ }^{28,29}$ Considering the effective utilization of $\mathrm{W}-\mathrm{Ni}$ catalyst, $0.45 \mathrm{~g}$ was chosen as an appropriate amount at the studied reaction conditions.

\subsection{Catalytic conversion of pretreated corn stalks on 15\% W- $5 \% \mathrm{Ni} /$ MSM catalyst}

Cellulose is bonded together with hemicelluloses and lignin to form a complex polymer by covalent bonding, various intermolecular bridges, and van der Waals forces. ${ }^{30}$ Therefore, for effective utilization of cellulose for conversion into highly valued products, lignocellulose must be pretreated to change the connection between constitutional units. Pretreatment with dilute acid and alkalis is common for efficiency and simplicity. Pretreatment with acid and alkalis can improve the conversion efficiency of lignocellulose to polysaccharide by breaking down lignin seals and disrupting the crystalline structure of cellulose. In general, an increase in cellulose content and/or a decrease in hemicellulose and lignin contents could improve the catalytic efficiency of cellulase for lignocellulosic materials. ${ }^{25,31,32}$ In our study, corn stalks were treated at various combinations of acidic and alkaline conditions, and the content of cellulose, hemicellulose, and lignin are shown in Table 2. Subsequently, the samples were subjected to $15 \% \mathrm{~W}-5 \% \mathrm{Ni} / \mathrm{MSM}$ catalyst under optimal conditions. Table 3 summarizes the EG and 1,2-PG yields from various corn-stalk samples. The pretreatment was beneficial to the catalytic conversion and the highest diols yield (62.60 wt\%) was obtained from a corn-stock sample pretreated with acid followed by alkali. The EG yield was improved from $4.09 \mathrm{wt} \%$ for an untreated sample to $48.21 \mathrm{wt} \%$ and $53.87 \mathrm{wt} \%$ for acid- and alkali-treated samples, respectively. These results clearly showed that the pretreatment methods of corn stalks were useful for the selective conversion of corn stalks into EG. However, the diols yields from corn-stock samples were inferior
Table 2 Contents in a corn stalk before and after pretreatment with acid and alkali

\begin{tabular}{|c|c|c|c|c|}
\hline $\begin{array}{l}\text { Pretreatment } \\
\text { method }\end{array}$ & Cellulose, \% & $\mathrm{HC}^{a}, \%$ & $\mathrm{AIL}^{b}, \%$ & $\mathrm{ASL}^{c}, \%$ \\
\hline Untreated & 42.02 & 15.88 & 12.17 & 15.87 \\
\hline $\begin{array}{l}\text { Pretreated } \\
\text { with acid }\end{array}$ & 52.32 & 10.83 & 6.34 & 18.79 \\
\hline $\begin{array}{l}\text { Pretreated } \\
\text { with alkali }\end{array}$ & 60.15 & 12.07 & 8.85 & 7.52 \\
\hline $\begin{array}{l}\text { Pretreated } \\
\text { with alkali } \\
\text { followed by acid }\end{array}$ & 75.12 & 9.80 & 6.06 & 5.48 \\
\hline $\begin{array}{l}\text { Pretreated with } \\
\text { acid followed } \\
\text { by alkali }\end{array}$ & 77.68 & 5.67 & 5.96 & 6.18 \\
\hline
\end{tabular}

to the result from microcrystalline cellulose. The yield of cellulose extraction from raw corn stock was limited, which might have been the main reason for differences between corn stalks and microcrystalline cellulose. ${ }^{33,34}$ To some extent, the increase in cellulose content of pretreated corn stalks and the high activity and selectivity of the $15 \% \mathrm{~W}-5 \% \mathrm{Ni} / \mathrm{MSM}$ catalyst were notable.

\subsection{Reusability of the catalyst}

One of the critical questions in correlating the conversion of cellulose results with supported catalysts is the stability of the catalyst under reaction conditions. In our study, the recycling performance of $15 \% \mathrm{~W}-5 \% \mathrm{Ni} / \mathrm{MSM}$ catalyst was examined. After completion of the reaction, $\mathrm{W}-\mathrm{Ni} / \mathrm{MSM}$ catalyst was recycled and applied to cellulose conversion, and a $30.30 \mathrm{wt} \%$ yield of polyol was obtained. To enhance the capability of recycled WNi/MSM catalyst, it was re-calcined and re-reduced. The regenerated $\mathrm{W}-\mathrm{Ni} / \mathrm{MSM}$ catalyst was also applied to the catalytic conversion of cellulose, and the corresponding result of the cycle test is shown in Fig. 3(b). We found that the polyol yield

Table 3 Catalytic conversion of various corn stalks into EG and 1,2-PG over $15 \% \mathrm{~W}-5 \% \mathrm{Ni} \mathrm{MSM}^{a}$

\begin{tabular}{|c|c|c|c|c|c|}
\hline \multirow{2}{*}{$\begin{array}{l}\text { Pretreatment } \\
\text { method }\end{array}$} & \multicolumn{2}{|l|}{ EG } & \multicolumn{2}{|l|}{ 1,2-PG } & \multirow{2}{*}{$\frac{\text { Total yield }}{\%}$} \\
\hline & $\mathrm{mg} \mathrm{L}^{-1}$ & $\%$ & $\mathrm{mg} \mathrm{L}^{-1}$ & $\%$ & \\
\hline Untreated & 205.02 & 4.09 & 524.71 & 10.53 & 14.62 \\
\hline $\begin{array}{l}\text { Pretreated } \\
\text { with acid }\end{array}$ & 263.17 & 5.33 & 575.45 & 11.50 & 16.83 \\
\hline $\begin{array}{l}\text { Pretreated } \\
\text { with alkali }\end{array}$ & 672.11 & 13.40 & 509.04 & 10.22 & 23.62 \\
\hline $\begin{array}{l}\text { Pretreated with } \\
\text { alkali followed } \\
\text { by acid }\end{array}$ & 2408.15 & 48.21 & 554.91 & 11.11 & 59.32 \\
\hline $\begin{array}{l}\text { Pretreated with } \\
\text { acid followed } \\
\text { by alkali }\end{array}$ & 2244.45 & 53.87 & 363.90 & 8.73 & 62.60 \\
\hline
\end{tabular}


declined gradually with increasing cycle time. In particular, the EG yield decreased from $72.90 \mathrm{wt} \%$ in the first run to $62.72 \mathrm{wt} \%$ in the second run. A similar situation was found in the third cycle. These results suggested that the capability of the reactivated W-Ni/MSM catalyst declined during cellulose conversion.

\subsection{Reaction mechanism}

.To gain more detailed insights into the decreased activity of the catalyst during the recycling test, the crystalline phase, micromorphology and physicochemical property of $15 \% \mathrm{~W}-$ $5 \% \mathrm{Ni} / \mathrm{MSM}$ catalyst were characterized by XRD spectroscopy, XPS, TEM, SEM and $\mathrm{N}_{2}$ adsorption-desorption. As compared with the XRD patterns of catalysts before and after the reaction, the analysis of recycled $\mathrm{W}-\mathrm{Ni} / \mathrm{MSM}$ catalyst revealed the phase transformation during the reaction of cellulose conversion. As exhibited in Fig. 4(a), the peak intensity of nickel $\left(2 \theta=44.36^{\circ}, 51.59^{\circ}\right.$ and $\left.76.0^{\circ}\right)$ disappeared, and the peak intensity of Wolfram $\left(2 \theta=40.3^{\circ}, 58.3^{\circ}\right.$ and $\left.73.3^{\circ}\right)$ weakened. New peaks at $24.9^{\circ}, 31.54^{\circ}, 36.5^{\circ}, 44.7^{\circ}, 54.6^{\circ}$ and $65.5^{\circ}$ were visible, and were assigned to $\mathrm{NiWO}_{4}$ (PDF\#15-0755). The crystal phase of $\mathrm{W}-\mathrm{Ni} / \mathrm{MSM}$ was turned mainly into $\mathrm{NiWO}_{4}$ after the reaction was complete. XPS characterization was used further to identify the chemical state of the $\mathrm{W}$ and $\mathrm{Ni}$ on $\mathrm{W}-\mathrm{Ni}$ / MSM. Fig. 5(a and b) show that $\mathrm{W}^{0}\left(E_{\mathrm{b}}=31.3 \mathrm{eV}\right.$ and $\left.31.36 \mathrm{eV}\right)$ and $\mathrm{Ni}^{\circ}\left(E_{\mathrm{b}}=852 \mathrm{eV}\right.$ and $\left.853 \mathrm{eV}\right)$ were the dominant species on the fresh $\mathrm{W}-\mathrm{Ni} / \mathrm{MSM}$ catalyst. ${ }^{35,36}$ However, there was a W $4 \mathrm{f}_{7 / 2}$ binging energy $\approx 35.6 \mathrm{eV}$, which was assigned to $\mathrm{W}^{6+}$ as $\mathrm{WO}_{3}{ }^{35,37}$ The phase of $\mathrm{WO}_{3}$ was not observed by XRD spectroscopy, which might have been due to the low quantity of $\mathrm{W}$ below the detection limit of XRD spectroscopy. As compared with the spectrum of $\mathrm{Ni} 2 \mathrm{p}_{3 / 2}$ and $\mathrm{W} 4 \mathrm{f}_{7 / 2}$ before and after the reaction (Fig. $5(\mathrm{a}-\mathrm{d})), \mathrm{Ni}^{0}$ was replaced by $\mathrm{Ni}^{2+}\left(E_{\mathrm{b}}=855.5 \mathrm{eV}\right)$, $\mathrm{Ni}^{3+}\left(E_{\mathrm{b}}=856.5 \mathrm{eV}\right)$ and $\mathrm{NiWO}_{4}\left(E_{\mathrm{b}}=857.3 \mathrm{eV}\right)$, and $\mathrm{W}^{0}$ was also replaced by $\mathrm{NiWO}_{4}\left(E_{\mathrm{b}}=35.6 \mathrm{eV}\right){ }^{35,36}$ After the reaction was complete, the chemical component on $\mathrm{W}-\mathrm{Ni} / \mathrm{MSM}$ catalyst was changed. This result was in good accordance with the XRD spectroscopy data reported above, and could explain the deactivation of $\mathrm{W}-\mathrm{Ni} / \mathrm{MSM}$ catalyst after use, suggesting that $\mathrm{NiWO}_{4}$ has low activity for the hydrolytic hydrogenation of cellulose. Amazingly, new reflection peaks were detected in the re-activated W-Ni/MSM catalyst. As displayed in Fig. 4(b), the reflections appeared at $2 \theta$ around $32.6^{\circ}, 35.9^{\circ}, 43.0^{\circ}, 47.1^{\circ}$, $60.58^{\circ}, 70.9^{\circ}$ and $75.5^{\circ}$, which were assigned to nickel tungsten (NiW) (PDF\#47-1172). This result indicated that the new crystalline phase was formed on re-activated $\mathrm{W}-\mathrm{Ni} / \mathrm{MSM}$ catalyst, which was distinct from the fresh catalyst. Further details of
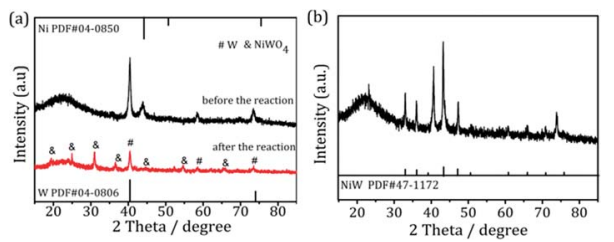

Fig. 4 XRD spectroscopy patterns of (a) W-Ni/MSM catalyst before and after the reaction and (b) the re-activated W-Ni/MSM catalyst.
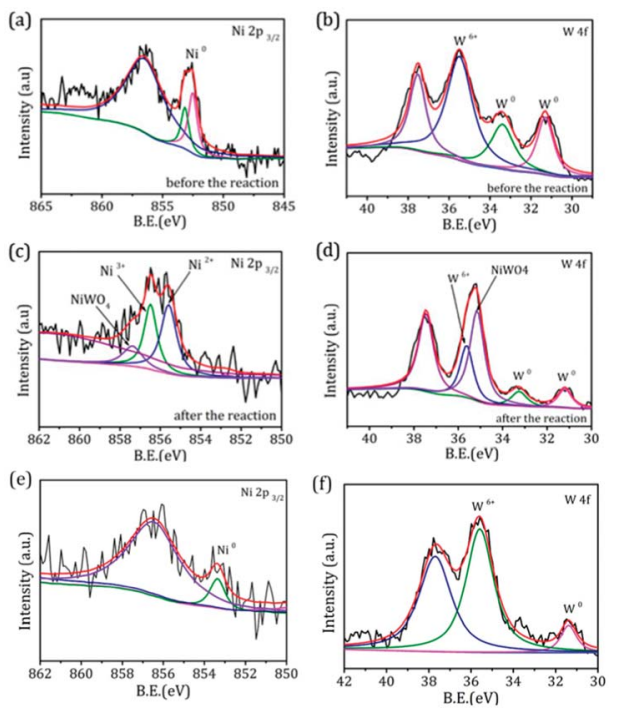

Fig. 5 XPS spectra of ( $a$ and c) Ni $2 p$ and ( $b$ and d) W $4 f$ of W-Ni/MSM catalyst before and after the reaction. XPS spectra of (e) Ni $2 p$ and (f) W $4 \mathrm{f}$ of the re-activated W-Ni/MSM catalyst.

the composition and chemical state were investigated by XPS, and the corresponding results are shown in Fig. 5(e and f). These data rendered $\mathrm{Ni}^{0}$ and $\mathrm{W}^{0}$, which was consistent with the XRD spectroscopy results. Hence, the different active phase of fresh and re-activated W-Ni/MSM catalyst may have been the main reason for the slight decrease in catalytic performance upon cellulose conversion. In addition, the average particle size of $\mathrm{W}-\mathrm{Ni} / \mathrm{MSM}$ catalysts was calculated by TEM. As shown in Fig. 6, the average nanoparticle size of used W-Ni/MSM catalyst was $4.6 \mathrm{~nm}$, which was slightly larger than that of fresh $\mathrm{W}-\mathrm{Ni} / \mathrm{MSM}$ catalyst $(4.2 \mathrm{~nm})$, suggesting particle agglomeration during the reaction. Also, the average particle size of the first re-activated $\mathrm{W}-\mathrm{Ni} / \mathrm{MSM}$ catalyst was almost
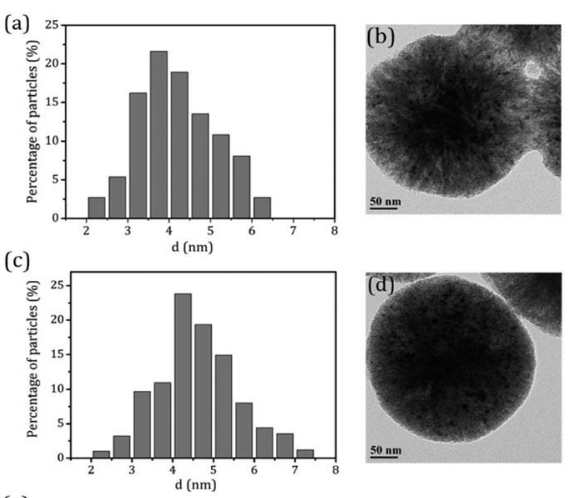

(e)
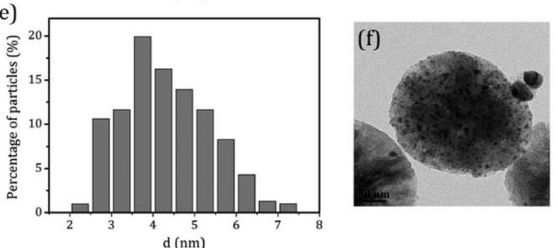

Fig. 6 TEM micrographs and metal particle size distributions on W$\mathrm{Ni} / \mathrm{MSM}$ catalyst ( $\mathrm{a}$ and $\mathrm{b}$ ) before and ( $\mathrm{c}$ and $\mathrm{d}$ ) after the reaction, and (e and f) the re-activated $\mathrm{W}-\mathrm{Ni} / \mathrm{MSM}$ catalyst. 


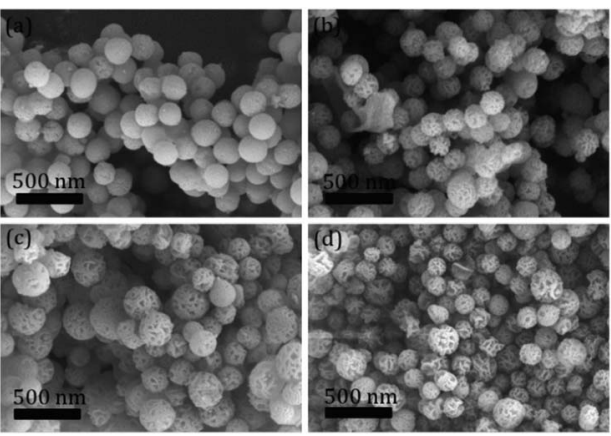

Fig. 7 SEM images of (a) fresh catalyst and $(b-d)$ the recycled $\mathrm{W}-\mathrm{Ni}$ / MSM catalyst after one, two and three runs.

identical to the data for the fresh catalyst. In summary, relatively small metal crystallite sizes remained during the reaction. To ascertain the cause of the decreased yields during the recycling test, the metal concentration in the liquid phase was quantified using ICP-AES. For $15 \% \mathrm{~W}-5 \% \mathrm{Ni} / \mathrm{MSM}$, the concentrations of $\mathrm{Ni}$ and $\mathrm{W}$ in the liquid phase after the first run were determined to be 0.77 and $7.58 \mathrm{mg} \mathrm{L}^{-1}$, respectively. After the second run, the concentrations of $\mathrm{Ni}$ and $\mathrm{W}$ in the liquid phase were 0.36 and $4.32 \mathrm{mg} \mathrm{L}^{-1}$, respectively. In summary, the leaching rate of $\mathrm{W}$ and $\mathrm{Ni}$ was $<0.7 \%$, much lower than that reported in the literature for this type of research. The morphology of the fresh and re-activated $\mathrm{W}-\mathrm{Ni} /$ MSM catalyst is shown in Fig. 7. The MSM continued to have regular spherical morphology, but the surface became rougher with increasing cycle time, suggesting that the structure of the support was partially broken during the reaction. Also, the irregular cratering on the surface of the MSM could cause mass-transfer resistance and spatial restriction, which results in the formation of byproducts and carbon deposition. ${ }^{21,27}$ In addition, a $\mathrm{N}_{2}$ adsorption-desorption experiment was conducted to provide additional information on the re-activated W-Ni/MSM catalyst. The BET surface area and pore volumes decreased after re-calcination and re-reduction. The specific surface area decreased from 164.08 to $73.6 \mathrm{~m}^{2} \mathrm{~g}^{-1}$ after recycling (data not shown).

\subsection{Reaction pathway}

It is known that soluble $\mathrm{H}_{x} \mathrm{WO}_{3}$ can convert into insoluble tungsten acid with decreasing solution temperature, and then the precipitate can become $\mathrm{NiWO}_{4}$ by contact with air. ${ }^{19,38}$ Based on the above discussion and experimental results, a reaction pathway for the catalyzed conversion of cellulose into polyol is illustrated in Fig. 8. In a water medium and hydrogen atmosphere, tungstic

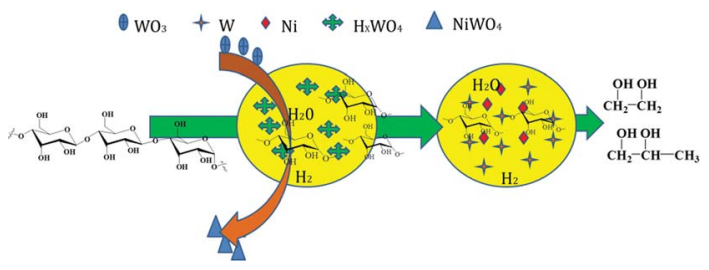

Fig. 8 The reaction pathway for the conversion of cellulose to EG and 1,2-PG on W-Ni/MSM catalyst. oxide on the solid catalyst dissolves in hot aqueous solution and forms the homogeneous catalyst $\left(\mathrm{H}_{x} \mathrm{WO}_{3}\right) . \mathrm{H}_{x} \mathrm{WO}_{3}$ and hot water can provide $\mathrm{H}^{+}$, which attacks to hydrogen and $\beta-1,4$-glycosidic bonds of cellulose to form glucan and oligosaccharide. Subsequently, the synergism between $\mathrm{W}$ and $\mathrm{Ni}$ act selectively on C-C cleavages and hydrogenation leads to conversion to EG. In addition, cellulose hydrolysis by $\mathrm{H}^{+9}$ and selective conversion into EG and $1,2-\mathrm{PG}^{13}$ are proposed.

\section{Conclusions}

W-Ni supported catalysts were prepared and tested for the hydrolytic hydrogenation of cellulose and pretreated corn stalks. $15 \% \mathrm{~W}-5 \% \mathrm{Ni} / \mathrm{MSM}$ catalyst showed excellent performance with an $82.2 \mathrm{wt} \%$ yield of polyol on conversion of cellulose, which was attributed to the synergistic effect of active sites and the support. Moreover, the transformation of active species on W-Ni/MSM catalyst was investigated, and a possible reaction pathway for the catalytic conversion of cellulose proposed. This pathway could be used to design promising catalysts for efficient conversion of biomass into renewable fuels.

\section{Conflicts of interest}

There are no conflicts to declare.

\section{Acknowledgements}

The authors thank the National Natural Science Foundation of China (21266023), National First-rate Discipline Construction Project of Ningxia (NXYLXK2017A04), and the Chunhui Project of Ministry of Education of China for financial support.

\section{Notes and references}

1 D. A. Bulushev and J. R. H. Ross, Catal. Today, 2011, 171, 113.

2 J. J. Bozell, Science, 2011, 329, 522-523.

3 Z. B. Zhang, Q. Lu, X. N. Ye, T. P. Wang, X. H. Wang and C. Q. Dong, BioEnergy Res., 2015, 8, 1263-1274.

4 Z. J. Tai, J. Y. Zhang, A. Q. Wang, J. F. Pang, M. Y. Zheng and T. Zhang, Chemsuschem, 2013, 6, 652-658.

5 M. Y. Zheng, J. F. Pang, R. Y. Sun, A. Q. Wang and T. Zhang, ACS Catal., 2017, 7, 1939-1954.

6 Q. Y. Liu, Y. H. Liao, T. J. Wang, C. L. Cai, Q. Zhang, N. Tsubaki and L. L. Ma, Ind. Eng. Chem. Res., 2014, 53, 12655-12664.

7 S. Ogo, T. Nishio, H. Sekine, A. Onda and Y. Sekine, Fuel Process. Technol., 2016, 141, 123-129.

8 S. Q. Xu, X. P. Yan, Q. Bu and H. A. Xia, Cellulose, 2017, 1-11. 9 Z. Z. Yang, R. L. Huang, W. Qi, L. P. Tang, R. X. Su and Z. M. He, Chem. Eng. J., 2015, 280, 90-98.

10 J. Y. Zhang, B. L. Hou, A. Q. Wang, Z. L. Li, H. Wang and T. Zhang, AIChE J., 2015, 60, 3804-3813.

11 A. Fukuoka and P. L. Dhepe, Angew. Chem., 2006, 45, 51615163. 
12 C. Luo, S. Wang and H. C. Liu, Angew. Chem., 2007, 119, 7636-7639.

13 N. Ji, T. Zhang, M. Y. Zheng, A. Q. Wang, H. Wang, X. D. Wang and J. G. G. Chen, Angew. Chem., 2008, 47, 8510-8513.

14 J. F. Pang, A. Q. Wang, M. Y. Zheng, Y. H. Huang, X. W. Chen and T. Zhang, Green Chem., 2012, 14, 614-617.

15 R. Y. Sun, M. Y. Zheng, J. F. Pang, X. Liu, J. H. Wang, X. L. Pan, A. Q. Wang, X. D. Wang and T. Zhang, ACS Catal., 2016, 6, 191-201.

16 M. Y. Zheng, A. Q. Wang, N. Ji, J. F. Pang, X. D. Wang and T. Zhang, Chemsuschem, 2010, 3, 63-66.

17 I. G. Baek, S. J. You and E. D. Park, Bioresour. Technol., 2012, 114, 684-690.

18 Z. Q. Xiao, R. Y. Sha, J. B. Ji and J. W. Mao, J. Fuel Chem. Technol., 2016, 44, 1225-1232.

19 Y. L. Cao, J. W. Wang, M. Q. Kang and Y. L. Zhu, J. Mol. Catal. A: Chem., 2014, 381, 46-53.

20 P. Rameshkumar, S. Saranya, K. Sujatha and R. Ramaraj, RSC Adv. , 2014, 5, 5038-5045.

21 T. Jiang, X. Wang, L. Zhang, J. Zhou and Z. Q. Zhao, Appl. Surf. Sci., 2016, 378, 181-190.

22 D. P. Li, R. X. Yi, J. W. Tian, J. H. Li, B. Y. Yu and J. Qi, Chem. Commun., 2017, 53, 8902-8905.

23 Á. Mayoral, V. Gascón, R. M. Blnco, C. Márquezálvarez and I. Díaz, APL Mater., 2014, 2, 6213-6219.

24 G. Y. Pan, Y. L. Ma, X. X. Ma, Y. G. Sun, J. M. Lv and J. L. Zhang, Chem. Eng. J., 2016, 299, 386-392.

25 L. Y. Cai, Y. L. Ma, X. X. Ma and J. M. Lv, Bioresour. Technol., 2016, 212, 42-46.
26 G. Y. Pan, Y. L. Ma, G. L. Lin, X. Q. Ding and Y. X. Ma, Polym. Bull., 2016, 10, 47-53.

27 Y. H. Liao, Q. Y. Liu, T. J. Wang, J. X. Long, Q. Zhang, L. L. Ma and Y. P. Li, Energy Fuels, 2014, 28, 5778-5784.

28 K. Y. Nandiwale, N. D. Galande, P. Thakur, S. D. Sawant, V. P. Zambre and V. V. Bokade, ACS Sustainable Chem. Eng., 2014, 2, 1928-1932.

29 B. Zhao, C. J. Chou and Y. W. Chen, Ind. Eng. Chem. Res., 2010, 49, 1669-1676.

30 Y. G. Sun, Y. L. Ma, L. Q. Wang, F. Z. Wang, Q. Q. Wu and G. Y. Pan, Carbohydr. Polym., 2015, 117, 486-493.

31 Y. Chen, M. A. Stevens, Y. M. Zhu, J. Holmes and H. Xu, Biotechnol. Biofuels, 2013, 6, 1-10.

32 Q. Q. Wu, Y. L. Ma, X. Chang and Y. G. Sun, Carbohydr. Polym., 2015, 129, 79-86.

33 I. Egüés, C. Sanchez, I. Mondragon and J. Labidi, Bioresour. Technol., 2012, 103, 239-248.

34 Q. Lu, Z. Cai, F. Lin, L. R. Tang, S. Q. Wang and B. Huang, ACS Sustainable Chem. Eng., 2016, 4, 2165-2172.

35 R. Juškènas, I. Valsiūnas, V. Pakštas, A. Selskis, V. Jasulaitienè, V. Karpavičienè and V. Kapočius, Appl. Surf. Sci., 2006, 253, 1435-1442.

36 S. H. Zhang, C. Shi, B. B. Chen, Y. L. Zhang and J. S. Qiu, Catal. Commun., 2015, 69, 123-128.

37 A. P. Shpak, A. M. Korduban, M. M. Medvedskij and V. O. Kandyba, J. Electron Spectrosc. Relat. Phenom., 2007, 156, 172-175.

38 A. Wang and T. Zhang, Acc. Chem. Res., 2013, 46, 1377-1386. 